\title{
Small group interventions for children aged 5-9 years old with mathematical learning difficulties
}

\section{Aunio, Pirjo}

Springer

2019

Aunio , P 2019 , Small group interventions for children aged 5-9 years old with mathematical learning difficulties . in A Fritz , V G Haase \& P Räsänen (eds), International Handbook of Mathematical Learning Difficulties : From the Laboratory to the Classroom . Springer, Cham ,pp. 709-732 . https://doi.org/10.1007/978-3-319-97148-3_41

http://hdl.handle.net/10138/327930

https://doi.org/10.1007/978-3-319-97148-3_41

acceptedVersion

Downloaded from Helda, University of Helsinki institutional repository.

This is an electronic reprint of the original article.

This reprint may differ from the original in pagination and typographic detail.

Please cite the original version. 
Aunio, P. (2019) Small group interventions for children aged 5-9 years old with learning difficulties in mathematics (pp 709-732) Fritz-Strantmann, A. \& Räsänen, P. (Eds.) International Handbook of M athematics Learning Difficulties. Springer.

Authors Copy

\title{
Small group interventions for children aged 5-9 years old with learning difficulties in mathematics
}

\author{
Pirjo Aunio \\ Professor, University of Helsinki, Finland \\ Visiting professor, University of Johannesburg \\ pirjo.aunio@helsinki.fi
}

\begin{abstract}
The research related to educational interventions for children with mathematical learning difficulties has been increasing steadily. In this chapter I focus on small group interventions for children aged 5-9 years old with learning difficulties in mathematics. First I describe the important issues: (1) who are the children having problems in mathematics, what do we mean with (special) education intervention, (3) what does Responsiveness to Intervention mean and (4) what intervention features have been found effective for children aged 5-9 years with learning difficulties in mathematics. Then I describe the research and developmental work that has been done in Finland on designing evidence-based Web services for educators related to mathematical learning difficulties, assessment and interventions. The two Web services are LukiMat and ThinkMath. Together, these two evidence-based Web services include the knowledge base, assessment batteries and intervention tools to be used in relation to mathematical learning difficulties in the age group 5-9 years.
\end{abstract}


webservice. To introduce the topic this chapter begins with description of few important concepts - who are the children having problems in mathematics, what do we mean with the concept of intervention, what does Responsiveness to Intervention

\section{Introduction}

The research related to educational interventions for children with mathematical learning difficulties has been increasing steadily. The main aim of this chapter is to describe the research and developmental work that has been done in Finland on designing evidence-based Web services for educators related to mathematical learning difficulties, assessment and interventions. The two Web services (LukiMat and ThinkMath) have been developed by two different, but related, research teams at the Niilo Mäki Institute (University of Jyväskylä) and the University of Helsinki. Together, these two evidence-based Web services include the knowledge base, assessment batteries and intervention tools to be used in relation to mathematical learning difficulties in the age group 5-9 years. The materials encourage educators to provide educational support for children according to the Responsiveness to Intervention model. In this chapter, the focus is in the developmental work on our small group intervention materials, hence ThinkMath webservice. To introduce the topic this chapter begins with description of few important concepts - who are the children having problems in mathematics, what do we mean with the concept of intervention, what does Responsiveness to Intervention mean and what intervention features have been found effective for children aged 5-9 years with learning difficulties in mathematics. 


\section{Learning difficulties in mathematics}

In the literature, there are several different terms used in relation to learning difficulties in mathematics, such as low performance in mathematics, learning difficulties in mathematics, mathematical learning disability, dyscalculia, mathematics disorder and many more. These various terms refer to different definitions (e.g., in terms of various cut-off scores) and different origins of the problems ranging from neurological dysfunctions to inappropriate opportunities to learn and practice mathematical skills (e.g., low socio-economical status of the child's family) (Ansari, 2015; Mazzocco, 2009). Geary (2013), suggests that children who score at or below the $10^{\text {th }}$ percentile on standardized mathematics achievement tests for at least two consecutive academic years are categorized as having an MLD (Mathematical learning disability). He further suggests that all children scoring between the $11^{\text {th }}$ and $25^{\text {th }}$ percentiles, inclusive, across two consecutive years are classed as LA (Low Achievers). The various terms are quite confusing, but when we talk about young children just starting their school career it seems to be appropriate to use the terms "low performing" or "mathematical learning difficulties" thus avoiding the "stronger terms" like "mathematical learning disability" and "dyscalculia", which clearly indicate to the possible neurological dysfunctions in the background of severe learning problems in basic arithmetic learning which is mostly visible in educational context only after couple of year math learning. For teacher it is also important to understand that mathematics performance is a continuum; there is no strict point where the problem starts.

\section{Intervention}


At the moment the concept "intervention" is a popular term and used with various meanings in education. Intervention can refer to the intervention programs which are used with children which have learning difficulties to change the originally bad learning prognosis (i.e. extra educational support). Intervention can also refer to the research design that is used to study children's development, in that the aim is to investigate what factors affect the learning. This approach is often used by developmental psychologists. In addition, intervention research design can be used to investigate the effects of a particular intervention program, which can then be published and used by educators. This approach is common among special education and educational psychology research.

The most important way to measure the effectiveness of the educational intervention programs is to study the increase in learning (i.e., achievement) of the children as a result of extra practice, hence intervention (Jimerson, Burns \& VanDerHeyden, 2007). The recommended and often used intervention research design includes a pretest (i.e., baseline measurement) and immediate and delayed post-test measurements with control groups. The intervention and control group design allows researchers and teachers to compare whether the children receiving intervention develop faster than their peers who are not getting extra attention for instance in mathematics learning. Researchers use a bit different approaches to judge if the intervention program is effective. In general, it is possible to say that an intervention program is effective if the children with low performance or learning difficulties progress better than their performance control peers. Secondly, it would be better results for intervention program if the children with low performances are able to maintain their head start compared with the control group even after the intervention phase has ended. Thirdly, the best results would be, in addition to the aforementioned 
effects, if the low-performing children closed the gap with their average performing peers. It is the researchers' task to explain these possibilities of effectiveness measuring to educators who need to make decisions related to how to support the children with learning difficulties (Jimerson Burns \& Van Der Heyden, 2007).

However, deciding which intervention program is best for the particular children is more complex than only deciding how effects needs to be detected. When we need to make a decision which intervention program to use, we need to compare programs and studies with different features. This task needs to be done carefully as intervention programs and studies can differ in various aspects, which can make comparison difficult (Fischer, Moeller, Cress \& Nuerk, 2013; Mononen, Aunio, Koponen \& Aro, 2014). The interventions can vary in terms of target children, comparison group, aims, setting, duration, mathematical content, conductor and professional developmental support, instructional design features which all can have impact, individually or together, on the intervention effectiveness (Fischer et al., 2013, Mononen et al. 2014).

The aims of intervention program can be remedial or preventive. Remedial intervention is needed when children have already been identified with severe mathematical learning difficulty (i.e., mathematical learning disability, dyscalculia) (Kuzian et al. 2011). Preventive intervention programs aim to avoid later learning problems. Preventive interventions are often used with younger children in preschool and primary grades and aim to assure that children learn well the very fundamental skills needed in later learning (Toll \& Van Luit, 2014). The focus groups can differ in intervention studies, they can be children who have diagnosed severe problems in learning mathematics (Kuzian et al. 2011), or children who have low achievement (i.e., performance) in mathematics (Toll \& Van Luit, 2012), or children who are at 
risk for learning difficulties based on their low socio-economical family background (Dyson, Jordan \& Glutting, 2011). Target group can also differ in their age, at the moment there is most research done with younger children (preschool and primary grades) (Bryant et al. 2008; Clarke et al., 2016) but also good progress is emerging with interventions for older students (Moser Opitz et al. 2016; Xin et al. 2017). There can be also differences in intervention setting: interventions can be conducted individually (Fuchs, Fuchs \& Compton, 2012; Hunt, Tzur \& Westenskow, 2016), in pairs (i.e. dyads) (Barnes et al. 2016), in small groups of children (3-8 children) (Bryant et al. 2008; Mononen \& Aunio, 2014; Moran, Swanson, Gerber \& Fung, 2014) or with whole classroom (Clarke et al., 2011). Related to intervention setting, the intervention can be core instruction thus taking place during regular mathematics lessons and replacing the math curriculum previously used in that classroom (Clarke et al. 2011). Intervention can be supplementary, during which children follow the average mathematics lessons and on top of that get extra educational support in skills they have individual needs (Powell et al. 2015). Time practiced is also important feature (i.e. exposure time for treatment), intervention programs can be short, with couple of hours or more extensive having more than 60 hours; also the time practiced at one session can differ a lot, for instance from 10 minutes to 60 minutes, and on top of that the number of sessions can differ. For instance Salminen and her colleagues (2015) investigated the differences in time used in computer assisted instruction research in the field of mathematical learning difficulties, and found them to vary between two weeks to whole semester, and sessions lasting from one minute to 60 minutes, there was also big variance in number of sessions; from 7 sessions to 50 sessions. Dennis and his colleagues (2016) reported the intervention length in minutes to vary between 400 minutes to 5400 minutes in mathematics learning small-group 
interventions for kindergarteners. Mathematical content can also vary. There are intervention programs that practice only some quite narrow skill, like numerical magnitude comparison and number line estimation in study of Sigler and Ramani (2009) and then there is intervention programs that practice several mathematical skills (Aunio, Hautamäki \& Van Luit, 2005; Barnes et al. 2011). The skills practiced can be very basic skills by nature (Sigler \& Ramani, 2009) or the focus can be on complex mathematical problem solving (Pfannenstiel, Bryant, Bryant, \& Porterfield, 2015; Sharp \& Dennis, 2017).

Interventions can be lead by researchers (Dyson, Jordan \& Glutting, 2011) or educators (Mononen \& Aunio 2014, 2016) (i.e. agent of intervention). If the intervention is conducted by the teacher there is a need for good professional development support for them so that she understands the principles and way of conducting the intervention the same way as has been the developers' idea, this way the ecological validity is secured (Cary, Clarke, Doabler, Smolkowski, Fien \& Baker, 2017). Interventions can include various instructional features such as explicit and systematic instruction (Toll \& Van Luit, 2014), use of visual representations in the introduction of mathematics ideas at concrete-representational-abstract (CRA) levels (Mononen \& Aunio, 2014, 2016), or use of computer-assisted-instruction (CAI) (Salminen et al. 2015). When the effectiveness of intervention is studied it is important to measure the impact related to comparative group of children, so that similar performance level children are compared with each other in similar learning environments, ideally the intervention is the only difference between participating children.

In summary, finding the best intervention program to support children is a complex issue. We need more results comparing similar intervention programs applied with 
similar way, to be able to be sure which are best ways to support children in their learning. Maybe good guideline for educator is to think what kind of mathematical learning problems children have (what skills are the ones the child lacks) and then look at the literature what kind of intervention programs have been developed to meet those learning needs. Then it is good for educator to think if the situation (children, learning needs, learning environment) is similar to that in which the particular intervention program has been found efficient.

\section{The features of effective instruction for children with mathematical learning difficulties}

There has been fast progress in the development intervention study methodology. At first there were individual intervention studies with quite small samples with convenience sampling but with quite a many control variables measure. Currently there seem to high demand of randomized control trials (RCT), large scale interventions and replication studies (e.g., Gersten Rolfhus, Clarke, Decker, Wilkins \& Dimino, 2015), to have reliable evidence that interventions are effective. An alternative way to understand the effectiveness of interventions in children's learning are the meta-analysis, reviews and systematic reviews which aims to summarize the previous intervention research results. They provide broader picture of the field of interventions than individual studies. Research reviews have produced some results with interventions for students with learning difficulties in mathematics (Chodura, Kuhn \& Holling, 2015; Codding, Burns \& Lukito, 2011; Gersten et al. 2009; Jitendra \& al. 2018; Kroesbergen \& van Luit 2003; Maccini, Mulcahy \& Wilson, 2007; Zhang 
$\&$ Xin, 2012) but only few have concentrate on young children (Dennis et al., 2016; Mononen Aunio, Koponen \& Aro , 2014).

In the review of Mononen et al. (2014) the interventions show from small to average effect sizes in improvement of the early numeracy skills of children aged 4 to 7 . Results indicate that different types of instructional design features, including explicit instruction, computer-assisted instruction (CAI), game playing, or the use of concreterepresentational-abstract levels in representations of math concepts, lead to improvements in mathematics performance. Therefore, rather than waiting to provide effective mathematics interventions at school (e.g., Baker et al., 2002; Slavin \& Lake, 2008), evidence-based programmes before the onset of school could be used to promote early numeracy skills, especially for low-performing children and to children from low SES environments.

In a recent meta-analysis, that included also younger children, Dennis et al. (2016) found that studies conducted at the kindergarten level yielded significantly weaker effects than studies conducted at the elementary level. Their results also showed that that interventions provided for students who had low math performance (at or below 35 th percentile) at the time of identification yielded strong intervention effects compared to those children performing above $35^{\text {th }}$ percentile. In addition interventions were more effective when they were provided by the researchers and researcher-trained graduate assistants, those provided by teachers and paraprofessionals produced weaker effects. Dennis and his colleagues (2016) found effective instructional variables to be: peer-assisted learning, explicit teacher led instruction (i.e. sequencing task from easy to difficult, task analysis), but interventions including the use of technology were least effective in improving the mathematics 
performance of students with MD. In addition, they found that intervention delivered in form of small-group instruction was a more effective for this group of students.

Dennis et al. (2016) replicates the results, at least partly, in previous meta-analysis concerning group-based interventions for children with mathematical learning difficulties (Baker, Gersten \& Lee, 2002; Swanson et al. 1999). These studies show that intervention studies that used explicit and strategic instructional procedures with students with learning difficulties have been found to have larger effect sizes compared to other instructional approaches (Baker et al., 2002; Chodura \& al., 2015; Gersten et al., 2009; Kroesbergen \& Van Luit, 2003; Mononen et al., 2014; Miller et al., 1998; Swanson et al., 1999). Explicit interventions included for instance sequencing of instruction in to logical sequences, providing clear presentation of subject matter, guided practice, independent practice and evaluating student learning on a regular basis. Explicit instruction often includes using Concrete-representationalabstract (CRA) sequence which have been found be effective instructional feature (Mononen et al., 2014; Miller et al., 1998; Xin \& Jitendra, 1998). Peer-assisted instruction has been found to be effective instructional feature with younger students (Baker et al., 2002; Kunsch et al., 2007). The effects of CAI in interventions for children with learning difficulties in mathematics are controversial, some found support (Miller et al., 1998; Kroesbergen and Van Luit, 2003, Mononen et al. 2014) and other ones are more critical (Dennis et al., 2011; Räsänen et al., 2010).

Previous meta-analysis (Chodura et al. 2015; Dennis et al., 2016; Jitendra et al. 2018; Mononen et al., 2012) have pointed some weaknesses in intervention studies in the field of mathematical learning difficulties. These are for instance, longitudinal effects 
of intervention is hard to study as there is no delayed measurement used, there is also not enough information to know how children with mathematical learning difficulties are identified (challenges with selection and outcome measurements, and cut-off criteria).

To know if the intervention studies published after latest meta-analysis (Dennis et al. 2012) have faced the pointed weaknesses. I made a small review with intervention studies published after 2014 in peer reviewed English journals, conducted in small group of children, applied at least quasi-experimental design with control group, focused on early numeracy (grade K-2) and children with learning difficulties in mathematics (Table 1). I found seven intervention studies published in peer reviewed English journals, all of the had been made in United States, in half of the studies they were all using some way to randomize students in the intervention and control group, they were used as supplementary and not replacing the core mathematics instruction. The children had low performance in early numeracy in six studies and possibly also in Clarke et al. (2016) in which teacher identified those children most likely benefit from small group instruction. In three studies children also had low income family background (Barnes et al. 2016; Dyson et al. 2015; Hassinger-Das, Jordan \& Dyson, 2015). Three (Clarke, Doabler, Smolkowski, Baker, Fien \& Cary 2016; Clarke, Doabler, Smolkowski, Kurtz-Nelson, Fien, Baker \& Kosty, 2016; Doabler, Clarke, Kosty, Kurtz-Nelson, Fien, Smolkowski \& Baker, 2016) out of seven studies used ROOTS intervention program developed by Clarke's research group in University of Oregon. All of the intervention studies focus on several mathematical skills. Cut-off criteria for low early performance varied between below 10 and below 35 percentile in standardized mathematics measurement, resulting quite big variation in skills in target group of children. In all of the studies a variety of standardized measurements 
were used (such as the Number Sense Brief Screener; SAT; TEMA-3:WJ-III) but also measurements designed by research group were used (EN-CBM, ASPENS) as outcome measurements. All seven studies reported significant intervention effects on children's early mathematics performance. But only three studies reported the delayed measurements results, confirming the lasting effects of interventions (Clarke, Doabler, Smolkowski, Kurtz-Nelson, Fien, Baker \& Kosty, 2016; Dyson, Jordan, Beliakoff \& Hassinger-Das, 2015; Hassinger-Das, Jordan \& Dyson, 2015). This small review confirms the pervious findings that explicit and systematic small group interventions have effects on early numeracy learning of low performing students. From European point of view it would be good to validate the findings also with samples outside United States. One challenge what science face here is that we have to develop ways how to describe our measurements, criteria and outcome, so that it is possible to relate them with measurements designed in other countries as well. In some countries we still lack good quality standardized measurements to identify mathematical learning difficulties and to follow the development in core skills. We still need more intervention studies to report the results from delayed measurement.

\section{Responsiveness to Intervention practice in supporting children with learning}

\section{difficulties}

At the beginning of the 21st century in the United States and Europe, the way to approach individuals with learning difficulties started to change. The focus shifted from diagnosing the individual in clinical settings to viewing individuals' learning as part of his or her learning context and emphasizing the early identification of learning difficulties to provide early interventions (i.e., Responsiveness to Intervention, RtI) 
(Hallahan, Pullen \& Ward, 2013). Responsiveness to Intervention can be seen as a pedagogical problem solving model, whose most important goal is to provide all children the most efficient instruction and intervention according to their needs (Jimerson et al., 2007). The instruction and support are divided most often into three levels of support: Tier 1, Tier 2 and Tier 3 (Riley-Tillman \& Burns, 2009), but other tier systems also exist (Fuchs, Fuchs \& Schumacher, 2011). Increasing levels means that the focus becomes more individualized, the support becomes more intensified and the support is provided over a longer period of time (Riccomini \& Smith, 2011). Bryant, Bryant, Gersten, Scammacca \& Chavez (2008) describes the relations between tiers so that Tier 1 consists of evidence-based core instruction for all children, Tier 2 includes supplemental intervention and ongoing progress monitoring for children who struggle with learning and Tier 3 is reserved for children who are struggling so much that they require intensive intervention. Previous research shows that research-based intervention programs that are provided with care and whose effectiveness has been investigated produce better learning results in the classroom than non-research based interventions (e.g. Jacob \& Parkinson, 2015; Slavin \& Lake, 2008).

In general, intervention programs can be used in classroom-level, small group and individual level. The most important difference between them is in focus. The classroom interventions mostly try to rise the level of whole group of learners, these can be called Tier 1 interventions if RtI is applied. The need for such interventions comes from the information about for instance the differences between schools or school districts. Small group interventions are designed to meet the specific learning needs of children who have learning difficulties. Individual interventions focus on learning difficulties of an individual student. Individual and small group interventions 
are often used in Tier 2 and 3 if RtI is applied. Small group interventions offer good possibilities for children to work together and practice skills that they have problems with tasks designed to their level of knowledge and needs. When there is only 4-8 children in a group it is easier for teacher to focus on children's learning, she is able to guide and coach their learning. In small group there is also possibilitie teacher to teach the target skill or topic, and then let children to practice together and individually. The main challenge with individual interventions is the demand of resources, at the moment schools do not have enough resources to offer individual interventions for children who needs support.

\section{Finnish evidence-based Web services for educators}

In Finland there has been a positive tendency over the last 10 years to boost teachers' levels of knowledge concerning individual learning differences in early reading and mathematical skills. The emphasis has been mainly on the early identification of learning difficulties and early intervention, with the aim of moving towards the Responsiveness to Intervention model and general (Tier 1), intensified (Tier 2) and special educational support (Tier 3) in the national education system (National core curriculum for basic education (2014/2016). The nationwide attempts in the field of early mathematics funded by the National Ministry of Education and Culture have been focused on producing evidence-based knowledge for educators and providing them with assessment tools and intervention programs to be used with children struggling with learning. I have been part of two teams that have designed two Web services for educators, namely LukiMat (www.lukimat.fi) and ThinkMath (http://blogs.helsinki.fi/thinkmath/in-english/). From these web services ThinkMath 
focuses on small group intervention programs, thus it is in focus of this chapter, LukiMat has been described in another paper (Aunio, 2016)

ThinkMath Web service development started at the University of Helsinki in 2011. It provides educators with hands-on intervention materials to be used with children, aged 5-8 years, who have problems with learning early mathematical skills. The main idea behind ThinkMath was that educators needed evidence-based materials for offline use, as there was a significant lack of computer devices for young children to use in early childhood settings or in early primary school grades. ThinkMath delivers intervention materials and knowledge to educators. There is a knowledgebase with evidence-based information concerning (1) mathematical skills development and learning difficulties, (2) thinking skills development, (3) motivational issues related to learning, (4) executive functions relevance for learning, and (5) (special) educational interventions. In the knowledge base we have provided short videos to explain the main ideas to educators as clear and fast as possible. The Material section offers group-based intervention materials for practicing for instance mathematical skills with children in small groups.

The base for the development of mathematics knowledge base and materials was the core factor model of the mathematical skills in children aged 5-8 years (Aunio \& Räsänen, 2015), which we originally developed for LukiMat. The model aimed to be a working model for the educators by presenting them with an overview of the most important skills that develop in early childhood, and secondly, aimed to make educators aware of the individual differences in early mathematical skills development. This model was based on a systematic literature review of longitudinal studies investigating mathematical development in this age group. We also analyzed the assessment batteries designed for identifying the children with potential learning 
difficulties in mathematics. We were able to categorise skills into four main groups of numerical factors that are most crucial to the development of mathematical skills: symbolic and non-symbolic number sense, understanding mathematical relations, counting skills, and basic skills in arithmetic (Aunio \& Räsänen 2015). In the ThinkMath materials we focused to practice these skills with children performing low.

The design related to pedagogical characteristics followed the findings in the research literature (Mononen et al., 2014). In the ThinkMath mathematical skills intervention programs, explicit teaching was one of the main guidelines along with several ways to practice the skills in focus (e.g., Gersten et al., 2008; 2009). In line with these recommendations, each lesson consists of a teacher-guided activity to model a new mathematical learning concept or strategy as well as guided and peer activities (e.g., hands-on activities with manipulatives, or card and board games based on the current topic) At the end of the lesson, there is a short, paper-and-pencil individual activity. Another general feature is that mathematical ideas are represented following the concrete, representational and abstract levels, thus giving meaning to abstract concepts by using visual representations (e.g. cubes, bundles of sticks, dot cards structured in tens and hundreds) (e.g., Mononen, 2014). The teacher manual includes 12-15 lesson plans of 35-45 minutes each. The lesson plans include specific instructions for teachers to follow in each activity. The manipulatives are made of low cost, everyday materials found in every classroom, combined with printable materials (e.g., dot and place value cards) included in the manual. During the development of the intervention materials, we worked closely with educators and investigated the effects of these intervention programs on low-performing children through quasiexperimental, pre-post measurement with intervention and control groups in different 
age groups (Mononen, Aunio \& Leijo, in revision; Mononen \& Aunio, 2014; Mononen \& Aunio, 2016).

\section{Studies with ThinkMath intervention programs}

The second grade intervention study (Mononen \& Aunio, 2014) was done with 88 children (M age 8 y. 2 m.) from four classes in schools located in two southern Finnish cities. The intervention program used in this study was Improving Mathematics Skills in the Second Grade (Mononen and Aunio, 2012a). It aims to practice number word sequence skills, counting and conceptual place value knowledge in the 1-1000 range and following the guidelines of explicit instructions. Children's mathematical skills were measured with the Assessment of Mathematics Skill in the Second Grade (AMS-2) (Aunio \& Mononen 2012a). It is a paper-andpencil test and measures (1) the number of forward and backwards word sequence skills, (2) numerical relational skills associated with base 10 and place value knowledge, (3) addition and subtraction word problems, 4) multi-digit addition and subtraction calculations with number symbols, all within a 1-1000 range and (5) addition and subtraction facts in the 1-20 range (40 items, 2 minutes' time). Children's thinking skills were assessed using the Assessment of Thinking Skills in the Second Grade (Hotulainen, Mononen \& Aunio, 2012a). Reading comprehension and fluency skills were measured using a standardized reading test for primary grades (Lindeman, 2005). Mathematical skills were measured three times: shortly before the intervention, immediately following the intervention and three months after the intervention. The thinking and reading skills were assessed at the first of the three time points. Children were divided in the low-performing intervention group $(n=11)$, 
the low performing control group $(n=13)$ and the typically performing control group $(n=64$ children). The intervention program lasted 6 weeks, and there were two 45 minute intervention sessions per week. The results demonstrated that the low performing intervention group made significant improvements in mathematics whole scale, and addition and subtraction facts but did not show significantly better scores compared to the low-performing control group. In addition, neither the intervention children nor the control children were able to perform at the same level of their peers following the intervention. There was no difference between low performance children in the control and intervention groups in terms of their thinking and reading skills. Although there were not many scientifically significant results, there was a trend to be seen that when children with low mathematical skills received extra support, their skills developed, but when the intensified instruction ended so did the development of their skills. This was especially true of arithmetical fluency skills.

Mononen and Aunio (2016) investigated the impact of ThinkMath intervention for Finnish first graders $(\mathrm{N}=151, \mathrm{M}$ age $=7 \mathrm{y} .2 \mathrm{~m}$.) with low numerical performance. The children were from nine classrooms located in three cities of Southern Finland. This program focused on increasing the counting skills knowledge, including the number sequence and enumeration skills in number range 1-20 (Mononen \& Aunio 2012b). The study applied a quasi-experimental design using control groups. The effects of intervention was examined using the Assessment of Mathematics Skills in the First Grade (Aunio \& Mononen 2012b). This group-based paper-and-pencil test includes mathematical tasks in the range from 1 to 100: (1) mathematical relational skills (i.e. number comparison); (2) counting skills (i.e. verbal and object counting) and (3) word problems (i.e. verbal addition and subtraction problems). Single-digit addition and subtraction facts in the range from 1 to 20 are also assessed (within a 2- 
minute time limit). A sum score for the subscales 1-3 (i.e. a combined scale) was used to identify the low-performing children. In addition, the relations between inductive reasoning (Assessment of Thinking Skills in the First Grade by Hotulainen, Mononen \& Aunio 2012b), language (reading fluency Allu by Lindeman 1998; listening comprehension Ytte test by Kajamies et al. 2003) and mathematical skills were examined. The intervention program was provided in small groups 12 times during 8 weeks, one session lasted about 45 minutes. The development of intervention children $(n=11)$ was compared to the development of low performing $(n=26)$ and typically performing $(n=114)$ children. The results showed significant effects of intervention, as the children in the intervention group made significantly greater gains in their mathematical performance from Time 1 to Time 2, compared with the low performing control and typically performing children. One important finding was that the children with low performance in mathematical skills showed lower performance also in their inductive reasoning and reading fluency skills than did children with typical performance. This means that supporting these children we need to also think how to support children's thinking skills early on. The main conclusion is that a relatively short counting skills intervention that applied explicit teaching showed promising effects in improving low-performing children's mathematical performance as a supplemental instruction.

In our kindergarten intervention study (Mononen, Aunio \& Leijo, in revision) the children in the low performing group were studied in more detail. The children in this group were children whose mathematics performances were below the $10^{\text {th }}$ percentile (i.e., very low performing, $\mathrm{n}=20$ ), and children whose mathematical performances lay between the $11^{\text {th }}$ and $25^{\text {th }}$ percentiles (i.e., low performing, $n=18$ ). The results were collected with a scale (Aunio \& Mononen, 2012c) measuring mathematical relational 
skills, number-word-sequence skills and counting skills which showed that the number children who reached an average level of performance at the post-test stage was higher among the group of children with low performance $(67 \%)$ versus those with very low performance (35\%) (Mononen, Tapola \& Aunio, 2015).

Westerholm and Aunio (submitted) investigated the effects of ThinkMathintervention for Finnish as a second language kindergarteners. There were nine children (M age 6 y. 8 m.) participating the study from one metropolitan area school.

In this study we used ThinkMath: Mathematical relational and counting skills 1-20 intervention program (Mononen \& Aunio 2012b) as was used in study of Mononen and Aunio (2016). Children practiced making comparisons on quantities and numbers using related concepts such as more and less and counting number sequences orally. In addition, counting objects and matching them with number words and number symbols were practiced. Based on the research literature concerning the learning challenges of children with instruction language as a second language (Arnold ym., 2002; Clements \& Sarama, 2008; Codding ym., 2009; Fuchs, Compton ym., 2008; Fuchs, Fuchs ym., 2008; Klein ym., 2008; Mercer \& Sams, 2006; Starkey, Klein \& Wakeley, 2004) we added motivation (i.e., prize) and explaining mathematical talk into the intervention program. Children's mathematics skills were measured with Early Numeracy Test (Van Luit, Van de Rijt \& Aunio, 2006) before, immediately after and five weeks after the intervention ended. The intervention program lasted 8 weeks having 35-75 min sessions twice a week. The results showed that ThinkMath intervention program with added motivating features and explicit mathematical talk was useful way to support the early mathematics learning of children that had Finnish as a second language and low mathematical performance in kindergarten. 
ThinkMath service has risen interest outside Finland also. We have now two international research projects, one in South Africa (e.g., Aunio, Mononen, Ragpot \& Törmänen, 2016) and one in Norway (https://thinkmathglobal.com). The most important scientific question still is, if it is possible to enhance the early mathematics learning of children with low performance with ThinkMath small groups interventions. In South Africa the learning context is quite different than in Finland, it will be interesting to see what kind of challenges the differences in teacher education, classroom organization and children's background offers us. Our project in Norway will increase our knowledge about how well our originally Finnish programs work in system where school starting age is different and teacher education is less research based than in Finland.

\section{Conclusion}

The existing intervention studies, meta-analysis and reviews have shown that it is beneficial to use small group mathematics interventions applying explicit and structurated with low performing young children.The work on Finnish ThinkMath project have not only shown that it is possible to develop evidence-based materials and that educators appreciate them, but also that Web services are a very efficient way to deliver such information and materials. Even though it is challenging to obtain significant and lasting learning effects with intervention studies in natural educational settings, these studies are essential in providing educators with evidence-based materials. In future we will need more research reviews and large-scale intervention studies to be able to understand how to support children with various age and needs in mathematical learning. 


\section{References}

Ansari, D. (2015). No more math wars - an evidence-based, developmental perspective on math education. Education Canada, September 2015. Retrieved from www.cea-ace.ca.

Arnold, D. H., Fisher, P. H., Doctoroff, G. L. \& Dobbs, J. (2002). Accelerating math development in Head Start classrooms. Journal of Educational Psychology, 94(4), 762-770.

Aunio, P. (2016) Finnish digital learning support for children with learning difficulties in mathematics. In Niemi, H. \& Jiyou, J. (Eds.) New ways to teach and learn in China and Finland: Crossing boundaries with technology. Peter Lang, Germany. Pp. 136-149.

Aunio, P., Hautamäki, J. \& Van Luit, J.E.H. (2005). Mathematical-thinking intervention programmes for preschool children with normal and low number sense. European Journal of Special Needs Education, 20,131-146.

Aunio, P., \& Mononen, R. (2012a). Assessment of Mathematical Skills in the Second Grade. Unpublished. Helsinki, Finland: University of Helsinki.

Aunio, P., \& Mononen, R. (2012b). Assessment of Mathematical Skills in the First Grade. Unpublished. Helsinki, Finland: University of Helsinki.

Aunio, P., \& Mononen, R. (2012c). Assessment of Mathematical Skills in the Kindergarten. Unpublished. Helsinki, Finland: University of Helsinki.

Aunio, P., Mononen, R., Ragpot, L., \& Törmänen, M. (2016) Early Numeracy Performance of South African School Beginners. South African Journal of Childhood Education, 6 (1) 1-8. DOI: http:// dx.doi.org/ 10.4102/ sajce.v6i1.496.

Aunio, P. \& Räsänen, P. (2015). Core numerical skills for learning mathematics in children aged five to eight years - a working model for educators. European Early Childhood Education Research Journal DOI:10.1080/1350293X.2014.996424

Baker, S., Gersten, R., \& Lee, D. (2002). A synthesis of empirical research on teaching mathematics to low-achieving students. The Elementary School Journal, 103, 51-73.

Barnes, M.A., Klein, A., Swank, P., Starkey, P., McClandliss, B., Flynn, K., Zucker, T., Huang, C-W., Fall, A-M. \& Roberts, G. (2016) Effects of tutorial interventions in mathematics and attention for low-performing preschool children. Journal of Research on Educational Effectiveness, 9 (4) 577-606. 
Bryant D. P., Bryant B. R., Gersten R. M., Scammacca N. N., Chavez M. M. (2008). Mathematics intervention for first- and second-grade students with mathematics difficulties: The effects of Tier 2 intervention delivered as booster lessons. Remedial and Special Education, 29, 20-32

Cary, M.G., Clarke, B., Doabler, C., Smolkowski, K., Fien, H. \& Baker, S. K., (2017). A Practitioner Implementation of a Tier 2 First-Grade Mathematics Intervention. Learning Disability Quaterly,

Chodura, S., Kuhn, J-T., \& Holling, H. (2015). Interventions for children with mathematical difficulties. Zeitsschrift fur Psychologie 223(2)129-144.

Clarke, B., Dobler, C.T., Smolkowski, K., Baker, S.K. , Fien, H. \& Strand Cary, M. (2016) Examining the efficacy of a tier 2 kindergarten mathematics intervention. Journal of Learning Disabilities, 49 (2) 152-165.

Clarke, B., Doabler, C. T., Smolkowski, K. Baker, S. K., Fien, H., Cary, M. S. (2016). Examining the efficacy of a tier 2 kindergarten mathematics intervention. Journal of Learning Disabilities, 49 (2) 152-165.

Clarke, B., Doabler, C., Smolkowski, K., Kurtz-Nelson, E., Fien, H., Baker S.K. \& Kosty, D. (2016) Testing the immediate and long-term efficacy of a tier 2 kindergarten mathematics intervention. Journal of Research on Educational Effeciveness, 9 (4) 607-634.

Clarke, B., Smolkowski, K., Baker, S., Fien, H., Doabler, C.T., \& Chard, D.J. (2011) The impact of comprehensive tier 1 core kindergarten program on the achievement of students at risk in mathematics. The Elementary School Journal, 111 (4) 561-584.

Clements, D. H. \& Sarama, J. (2008). Experimental evaluation of the effects of a research-based preschool mathematics curriculum. American Educational Research Journal, 45(2), 443-494

Clements. D.H. Sarama, J., Spitler, M.E., Lange, A.A., \& Wolfe, C. (2011) Mathematics learned by young children in an intervention based on learning trajectories: A large-scale cluster randomized trial. Journal for Research in Mathematics education, 42 (2) 127-166.

Codding, R. S., Chan-Iannetta, L., Palmer, M. \& Lukito, G. (2009). Examining a classwide application of cover-copy-compare with and without goal setting to enhance mathematics fluency. School Psychology Quarterly, 24(3), 173-185.

Codding, R.S., Burns, M.K., \& Lukito, G. (2011) Meta-analysis of mathematic Basic Fact Fluency Interventions: A component analysis. Learning Disabilities Research and Practice, 26, 36-47. 
Dennis, S.M., Sharp, E., Chovanes, J., Thomas, J., Burns, R. M., Custer, B., \& Park, J. (2016). A meta-analysis of empirical research on teaching students with mathematics learning difficulties. Learning Disabilities Research \& Practice, 31 (3) $156-168$.

Doabler, C.T., Clarke, B., Kosty, D.B., Kurtz-Nelson, E., Fien, H., Smolkowski, K., \& Baker, S.K. (2016) Testing the efficacy of a tier 2 mathematics intervention: A conceptual replication study. Exceptional Children, 83 (1) 92-110.

Dyson, N., Jordan, N.C., Beliakoff, A. \& Hassinger-Das, B. (2015) A kindergarten number-sense intervention with contrasting practice condition for lowachieving children. Journal for Research in Mathematics Education 46 (3) 331-370.

Dyson, N. I., Jordan, N.C., \& Glutting, J. (2011). A number sense intervention for low-income kindergartners at risks for mathematics difficulties. Journal of Learning Disabilities, 46 (2) 166-181.

Fischer, U., Moeller, K., Cress, U., \& Nuerk, H.-C. (2013). Interventions supporting children's mathematics school success: A meta-analytic review. European Psychologist, 18(2), 89-113.

Fuchs, L. S., Compton, D. L., Fuchs, D., Hollenbeck, K. N., Craddock, C. F. \& Hamlett, C. L. (2008). Dynamic assessment of algebraic learning in predicting third graders' development of mathematical problem solving. Journal of Educational Psychology, 100(4), 829-850.

Fuchs L. S., Compton D. L., Fuchs D., Paulsen K., Bryant J. D., Hamlett C. L. (2005). The prevention, identification, and cognitive determinants of math difficulty. Journal of Educational Psychology, 97(3), 493-513

Fuchs, L. S., Fuchs, D., \& Compton, D.L., (2012) Intervention effects for students with comorbid forms of learning disability: Understanding the needs of nonresponders. Journal of Learning Disabilities 46 86) 534-548.

Fuchs, L. S., Fuchs, D., Craddock, C., Hollenbeck, K. N., Hamlett, C. L. \& Schatschneider, C. (2008). Effects of small-group tutoring with and without validated classroom instruction on at-risk students' math problem solving: Are two tiers of prevention better than one? Journal of Educational Psychology, 100(3), 491-509.

Fuchs, L. S., Fuchs, D. \& Schumacher, R.F. (2011). A two-tiered RTI system for improving word-problem performance among students at risk for mathematics difficulty. In Gersten, R. \& Newman-Conchar, R. (Eds.), Understanding RTI in Mathematics - Proven methods and applications. Paul Brookes, Baltimore, Maryland. pp 85-108. 
Geary, D.C. (2013). Learning Disabilities in Mathematics. Recent advances. In Swanson, H.L., Harris, K.R., \& Graham, S. (Eds.), Handbook of Learning Disabilities. 2nd edition. The Guilford Press, New York. Pp. 239-255.

Gersten, R., Chard, D. J., Jayanthi, M., Baker, S.K., Morphy, P. \& Flojo, J. (2008). Mathematics Instruction for students with learning disabilities or difficulty learning mathematics. A synthesis of the intervention research. Portsmouth, $\mathrm{NH}: \mathrm{RMC}$ Research Corporation, Centre on Instruction.

Gersten, R., Chard, D., Jayanthi. M., Baker, S.K., Morphy, P., \& Flojo, J. (2009). Mathematics Instruction for students with learning disabilities: A metaanalysis of instructional components. Review of Educational Research, 79 (3) 1202-1242.

Gersten R. M., Rolfhus E., Clarke B., Decker L. E., Wilkins C., Dimino J. (2015). Intervention for first graders with limited number knowledge: Large-scale replication of a randomized controlled trial. American Educational Research Journal, 52, 516-546. doi:10.3102/0002831214565787

Hallahan, D. P., Pullen, P. C. \& Ward, D. (2013). A brief history of the field of learning disabilities. In Swanson, H.L., Harris, K. R. \& Graham S. (Eds.), Handbook of Learning Disabilities. 2nd edition. Guilford Press, New York. Pp 15-32)

Hassinger-Das, B., Jordan, N.C. \& Dyson, N. (2015) Reading stories to learn math Mathematics vocabulary instruction for children with early numeracy difficulties. The elementary school journal, 116 (2) 242-264.

Hotulainen, R., Mononen, R., \& Aunio, P. (2012a). Assessment of Thinking Skills in the Second Grade. Unpublished. Helsinki, Finland: University of Helsinki.

Hotulainen, R., Mononen, R., \& Aunio, P. (2012b). Assessment of Thinking Skills in the First Grade. Unpublished. Helsinki, Finland: University of Helsinki.

Hunt, J.H., Tzur, R. \& Westenskow, A. (2016) Evolution of unit fraction conceptions in two fifth-graders with learning disability: An exploratory study.

Mathematical Thinking and Learning, 18 (3) 182-208.

Jacob, R. \& Parkinson, J. (2015) The potential for school-based interventions that target executive function to improve academic achievement: A review. Review of Educational Research, 85 (4) 512-552.

Jimerson, S. R., Burns, M. K. \& VanDerHeyden, A.M. (2007). Handbook of Response to Intervention. The science and practice of assessment and intervention. Springer, New York. 
Jitendra, A.K., Lein, A.E., Im, S-h, Alghamdi, A.A., Hefte, S.B., Mouanoutoua, J. (2018) Mathematical interventions for Secondary students with learning disabilities and mathematics difficulties: A Meta-analysis. Exceptional Children, 84 (2) 177-196.

Kajamies, A., Poskiparta, E. \& Annevirta T., Dufva, M. \& Vauras, M. (2003) YTTE Luetun ja kuullun ymmärtäminen ja lukemisen sujuvuuden arviointi (Assessment of reading and listening comprehension and reading fluency). University of Turku, Oppimistutkimuskeskus OTUK, Turku, Finland.

Kucian, K., Grond, U., Rotzer, S., Henzi, B., Schönmann C. et al. (2011) Mental number line training in children with developmental dyscalculia. Neuroimage, 57 (3) $782-795$.

Klein, A., Starkey, P., Clements, D., Sarama, J. \& Iyer, R. (2008). Effects of a prekindergarten mathematics intervention: A randomized experiment. Journal of Research on Educational Effectiveness, 1(3), 155-178.

Kroesbergen, E. H., \& Van Luit, J. E. H. (2003). Mathematics interventions for children with special educational needs. A meta-analysis. Remedial and Special Education, 24(2), 97-114.

Kunsch, C. A., Jitendra, A. K., \& Sood, S. (2007). The effects of peer-mediated instruction in mathematics for students with learning problems: A research synthesis. Learning Disabilities Research \& Practice, 22(1), 1-12.

Lindeman, J. (2005). ALLU: Ala-asteen Lukutesti: Käyttäjän käsikirja [ALLU: Reading Test for Primary Grades: User's Manual]. Turku, Finland: University of Finland, Centre of Learning Research.

Maccini, P., Mulcahy, C.A. \& Wilson, M.G. (2007) A Follow-up of Mathematics Interventions for Seconday Students with Learning Disabilities. Learning Disabilities, Research and Practice, 22 (1) 58-74.

Mazzocco M.M.M. (2009). Defining and differentiating mathematical learning disabilities and difficulties. In Mazzocco, M.M.M. \& Berch, D.B. Why is math so hard for some children? The nature and origins of mathematical learning difficulties and disabilities. Paul H. Brookes, Baltimore, Maryland. pp. 29-48.

Mercer, N. \& Sams, C. (2006). Teaching children how to use language to solve maths problems. Language and education, 20(6), 507-528.

Miller, S. P., Butler, F. M., \& Lee, K. (1998). Validated practices for teaching mathematics to students with learning disabilities: A review of literature. Focus on Exceptional Children, 31(1), 1-24. 
Mononen, R. (2014). Early mathematics interventions - Supporting young children with low performance in mathematics. PhD-dissertation, University of Helsinki, Finland.

Mononen, R., \& Aunio, P. (2012a). Improving mathematics skill in the second grade. An intervention program. Unpublished. Helsinki, Finland: University of Helsinki.

Mononen, R., \& Aunio, P. (2012b). Improving mathematics skill in the first grade. An intervention program. Unpublished. Helsinki, Finland: University of Helsinki.

Mononen, R., \& Aunio, P. (2012c). Improving mathematics skill in the kindergarten. An intervention program. Unpublished. Helsinki, Finland: University of Helsinki.

Mononen, R. \& Aunio, P. (2014). A mathematics Intervention for Low-performing Finnish Second Graders: Findings from a Pilot Study. European Journal of Special Needs Education 29 (4) 457-473. DOI: 10.1080/08856257.2014.922794.

Mononen, R. \& Aunio, P. (2016) Math intervention for low-performing first graders. South African Journal of Childhood Education, 6 (1) a407.

Mononen, R., Aunio, P., Koponen, T., \& Aro, M. (2014) A Review of early numeracy interventions: Effectiveness and pedagogical implementation. International Journal of Early Childhood Special Education, 6, 1, s. 25-54

Mononen, R., Aunio, P. \& Leijo, S. Matemaattisten taitojen harjoittelun vaikutukset matematiikan taidoiltaan heikkojen esiopetusikäisten lasten osaamiseen (The effects of mathematical intervention on low performing children's performance in kindergarten). In revision.

Mononen, R., Tapola, A. \& Aunio, P. (2015). Intensified mathematical support for low performing kindergarteners. Paper presentation in symposium. Conference of European Association for Research on Learning and Instruction. 25-29 August 2015, Limassol, Cyprus.

Moran, A. S., Swanson, H.L., Gerber, M. M. \& Fung, W. (2014) The effects of paraphrasing interventions on problem solving accuracy for children at risk for math disabilities. Learning Disabilities Research \& Practice 29 (3) 97-105.

Moser Opitz, E.. Freesemann, O. Prediger, S., Grob, U., Matull, I. \& Hasmann, S. (2016) Remediation for students with mathematics difficulties: An intervention study in middle schools. Journal of Learning Disabilities, 1-13. 
National core curriculum for basic education (2014/2016). Finnish National Board of Education. Helsinki, Finland.

Pfannenstiel, K., H., Bryant, D.P., Bryant, B., \& Porterfield, J.A. (2015). Cognitive strategy instruction for teaching word problems to primary-level struggling students. Intervention in School and Clinic, 50 (5) 291-296

Powell, S.R., Fuchs, L. S., Cirino, P.T., Fuchs, D., Compton, D.L. \& Changas, P.C. (2015) Effects of a multitier support system on calculation, word problem and prealgebraic performance among at-risk learners. Exceptional Children, 81 (4) 443-470.

Riccomini, P. J. \& Smith, G. W. (2011). Introduction of Response to Intervention in Mathematics. In Gersten R. \& Newman-Gonchar, R. (Eds.), Understanding RTI in Mathematics - Proven Methods and Applications. Paul H. Brookes, Baltimore, Maryland. Pp. 1-16.

Riley-Tillman, T. C., \& Burns, M. K. (2009). Evaluating Educational Interventions: Single-Case Design for Measuring Response to Intervention. New York, NY: Guilford Press.

Räsänen, P. Salminen, J., Wilson, A., Aunio, P. \& Dehaene, S. (2009) Computerassisted intervention for early number skills in children with low numeracy: A short review and a randomized controlled trial. Cognitive Development, 24, 4, 450-472.

Salminen J.B., Koponen, T.K., Leskinen, M., Poikkeus, A-M., \& Aro, M. (2015) Individual variance in responsiveness to early computerized mathematics intervention. Learning and Individual Differences, 43, 124-131.

Sharp, E., \& Dennis, M.S. (2017) Model drawing strategy for fraction word problem solving of fourth-grade students with learning disabilities. Remedial and Special Education, 38(3) 181-192.

Siegler, R.S., \& Ramani, G.B. (2009) Playing linear board games - but not circular ones - improves low-income preschoolers' numerical understanding. Journal of Educational Psychology, 101 (3) 545-560.

Slavin, R.E. \& Lake, C. (2008). Effective programs in elementary mathematics: A best-evidence synthesis. Review of Educational Research 78 (3) 427-515.

Starkey, P., Klein, A., Wakeley, A. (2004). Enhancing young children's mathematical knowledge through a pre-kindergarten mathematics intervention. Early Childhood Research Quarterly, 19(1), 99-120. 
Swanson, H. L., Hoskyn, M., \& Lee, C. (1999). Interventions for students with learning disabilities: A meta-analysis of treatment outcomes. New York: Guilford.

Toll, S.W.M. \& Van Luit, J.E.H. (2014). Effects of remedial numeracy instruction throughout kindergarten starting at different ages. Evidence from a large-scale longitudinal study. Learning and Instruction, 33, 39-49.

Toll, S. W. M. \& Van Luit, J.E.H. (2012) Early Numeracy Intervention for lowperforming kindergartners. Journal of Early Intervention, 34 (4) 243-264.

Van Lujt, J. E. H.; Van de Rijt, B. A. M. \& Aunio, P. (2006). Lukukäsitetesti. (Early Numeracy Test) Psykologien kustannus Oy, Helsinki, Finland

Westerholm, A. \& Aunio, P. (submitted). Maahanmuuttajataustaisten lasten varhaisten matemaattisten taitojen interventiotutkimus (ThinkMathintervention for Finnish as a Second Language kindergarteners).

Zhang, D. \& Xin, Y.P. (2012) A follow-up meta-analysis for word-problem-solving interventions for students with mathematics difficulties. The Journal of Educational Research, 105 (5) 303-318.

Xin, Y. P., \& Jitendra, A. K. (1999). The effects of instruction in solving mathematical word problems for students with learning problems: A metaanalysis. The Journal of Special Education, 32(4), 207-225.

Xin, Y.P., Tzur, R., Hord, C., Liu, J., Par, J.Y. \& Si, L. (2017) An intelligent tutorassisted mathematics intervention program for students with learning difficulties. Learning Disability Quaterly, 40 (1) 4-16. 


\begin{tabular}{|c|c|c|c|c|c|c|c|c|c|c|}
\hline \multirow[t]{2}{*}{ Table 1} & \multirow[b]{2}{*}{ Title } & \multicolumn{3}{|c|}{ Sample } & \multicolumn{6}{|c|}{ Intervention } \\
\hline & & Age & At-risk status & Number of participants & Duration & Leader & Instructional design feature & Math Measure & Pre-post Effect size & $\begin{array}{l}\text { Follo } \\
\text { W-up } \\
\text { (Yes/ } \\
\text { No) }\end{array}$ \\
\hline $\begin{array}{l}\text { Barnes, Klein, } \\
\text { Swank, Starkey, } \\
\text { McCandliss, } \\
\text { Flynn, Zucker, } \\
\text { Huang, Fall \& } \\
\text { Roberst (2016) }\end{array}$ & $\begin{array}{l}\text { Effects of tutorial } \\
\text { interventions in } \\
\text { mathematics and } \\
\text { attention for low- } \\
\text { perfoming } \\
\text { preschool children. }\end{array}$ & 4.50 years & $\begin{array}{l}\text { low performance } \\
\text { (below 25th } \\
\text { percentile in TEM A- } \\
\text { 3) and low-income } \\
\text { family }\end{array}$ & $\begin{array}{l}\mathrm{N}=541(\mathrm{M}+\mathrm{Att} \mathrm{n}=181 ; \mathrm{M} \\
\text { only } \mathrm{n}=180 ; \text { Business-as- } \\
\text { usual (BaU) } \mathrm{n}=180)\end{array}$ & $\begin{array}{l}24 \text { weeks } \\
(1920 \\
\mathrm{min})\end{array}$ & Researcher & $\begin{array}{l}\text { explicit +systematic instruction, } \\
\text { cumulative review; teaching to } \\
\text { mastery, scaffolding, progress } \\
\text { monitoring. Pre-K-M athematical } \\
\text { Tutorial (PKMT) }\end{array}$ & $\begin{array}{l}\text { Child M ath Assessment (CMA) (Starkey \& } \\
\text { Klein 2012); Test of Early Mathematics } \\
\text { Ability, 3rd ed. (TEM A-3) Ginsburg \& } \\
\text { Baroody 2003) }\end{array}$ & $\begin{array}{l}\text { In independent contrats with } \\
\text { BaU group, both the } M+A T T \\
\text { group }(E S=43) \text { and the } M \text { only } \\
\text { group }(E S=60) \text { had greater } \\
\text { math knowledge at posttest } \\
\text { CMA. }\end{array}$ & No \\
\hline $\begin{array}{l}\text { Clarke, Doabler, } \\
\text { Smolkowski, } \\
\text { Baker, Fien \& } \\
\text { Cary (2016) }\end{array}$ & $\begin{array}{l}\text { Examining the } \\
\text { efficacy of a tier } 2 \\
\text { kindergarten } \\
\text { mathematics } \\
\text { intervention. }\end{array}$ & 5.54 years & $\begin{array}{l}\text { teacher identified } \\
\text { five lowest } \\
\text { performing children } \\
\text { who would benefit } \\
\text { from small group } \\
\text { math instruction. } \\
\text { Of the } 122 \text { children } \\
91 \% \text { scored at or } \\
\text { below } 10 \text { th } \\
\text { percentile in TEM A }\end{array}$ & $\begin{array}{l}N=140 \text { (intervention } n=67 \text {, } \\
\text { control } n=73 \text { ) }\end{array}$ & $\begin{array}{l}20 \text { weeks } \\
(1200 \\
\text { minutes) }\end{array}$ & Researcher & $\begin{array}{l}\text { ROOTS (whole number } \\
\text { understanding), explicit \& } \\
\text { systematic instruction: modeling } \\
\text { and demonstrating, quided } \\
\text { practice, visual represenatations, } \\
\text { feedback. M ath verbalization. } \\
\text { Systematic instruction: prioritizing } \\
\text { instruction around critical } \\
\text { content, connecting new content } \\
\text { with students' bakground } \\
\text { knowledge, selecting and } \\
\text { sequencing instructional } \\
\text { examples and scaffolding } \\
\text { instruction. }\end{array}$ & $\begin{array}{l}\text { Test of Early M athematics Ability (TEMA } \\
\text { (Pro-Ed, 2007), Early Numeracy Curriculum- } \\
\text { Based M easurement (EN-CBM, Clarke \& } \\
\text { Shinn, 2004) }\end{array}$ & $\begin{array}{l}\text { Found statistically significant } \\
\text { gains among the intervention } \\
\text { students over those in control } \\
\text { classrooms on TEM A standard } \\
\text { scores ( } t=2.19 \text {, df } 27, p=0371) \\
\text { but not in the EN-CBM total } \\
\text { score }(t=1.35, \text { df } 27, p=1870) \text {. } \\
\text { The correspondend to Hedge's } g \\
\text { effect sizes of .38 for the TEM A } \\
\text { standard score and .30 for the } \\
\text { EN-CBM. }\end{array}$ & s. \\
\hline $\begin{array}{l}\text { Clarke, Doabler, } \\
\text { Smolkowski, } \\
\text { Kurtz-Nelson, } \\
\text { Fien, Baker \& } \\
\text { Kosty (2016) }\end{array}$ & $\begin{array}{l}\text { Testing the } \\
\text { immediate and } \\
\text { long-term efficacy } \\
\text { of tier } 2 \\
\text { kindergarten } \\
\text { mathematics } \\
\text { intervention. }\end{array}$ & 5.2 years & $\begin{array}{l}\text { Low performance. } \\
\text { Children qualified } \\
\text { for the intervention } \\
\text { if they scored of } 20 \\
\text { or less on the NSB } \\
\text { (Jordan et al 2008) } \\
\text { and had composite } \\
\text { score on ASPENS } \\
\text { that placed in the } \\
\text { srtatigic or } \\
\text { intensive range } \\
\text { (Clarke, Gersten et } \\
\text { al. 2011) }\end{array}$ & $\begin{array}{l}\mathrm{N}=290 \text { (two-student ROOTS } \\
\text { condition ( } \mathrm{n}=58 \text { ); five- } \\
\text { student ROOTS condition } \\
\text { ( } \mathrm{n}=145 \text { ), no-tratment } \\
\text { control condition ( } \mathrm{n}=87 \text { ) }\end{array}$ & $\begin{array}{l}10 \text { weeks } \\
(1000 \\
\mathrm{min})\end{array}$ & Researcher & $\begin{array}{l}\text { ROOTS (whole number } \\
\text { understanding), Explicit \& } \\
\text { systematic. Explicit instruction: (a) } \\
\text { teacher modeling, (b) deliberate } \\
\text { practice (incl scaffolding) (c) } \\
\text { visual representations of } \\
\text { mathematics (d) academic } \\
\text { feedback. }\end{array}$ & $\begin{array}{l}\text { ROOTS Assessment of of EARLY Numeracy } \\
\text { Skills (RAENS) (Doabler, et al. 2012); } \\
\text { Assessing Student Proficiency in Early } \\
\text { Number Sense (ASPENS) (Clarke, Gersten et } \\
\text { al. 2011); Number Sense Brief (NSB) } \\
\text { Screener (Jordan et al. 2008); Test of Early } \\
\text { M athematics Ability-Third Edition (Ginsburg } \\
\text { \& Baroody 2003); The Standford } \\
\text { Achievement Test- Tenth Edition (SAT). }\end{array}$ & 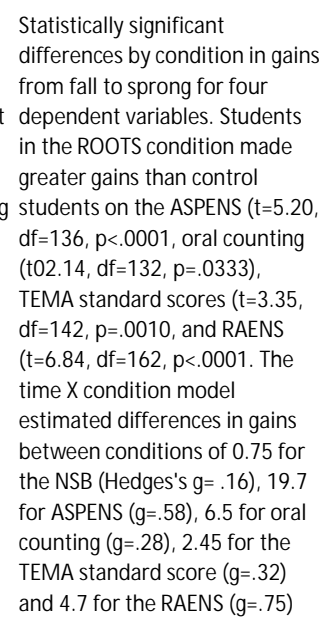 & ses \\
\hline
\end{tabular}


Doabler, Clarke, Testing the efficacy

Nelson, Fien, mathematics

$\begin{array}{ll}\text { Smolkowski \& intervention: } & \\ \text { Baker (2016) } & \text { conceptual }\end{array}$ Kosty, Kurtz- of a tier 2

replication study.

Low performance. $\quad \mathrm{N}=319$ (ROOTS-small Children with both condtion (n=67), the an NSB score of 20 ROOTS-Large $(n=162)$ and or less and an control condition $(n=90)$ ASPENS compos

score in the

"stratetic" or

"intensive" ranges

were concidered at

risk for MD and

eligible for

5.2 years

\begin{tabular}{|c|c|c|c|c|}
\hline $\begin{array}{l}\text { Dyson, Jordan, } \\
\text { Beliakoff \& } \\
\text { Hassinger-Das } \\
\text { (2015) }\end{array}$ & $\begin{array}{l}\text { A kindergarten } \\
\text { number-sense } \\
\text { intervention with } \\
\text { contrasting } \\
\text { conditions for low- } \\
\text { achieving children }\end{array}$ & 5.5 years & $\begin{array}{l}\text { Low income and } \\
\text { low performance. } \\
\text { Below 25th } \\
\text { percentile (number } \\
\text { sense screener, } \\
\text { Jordan et al. 2010) }\end{array}$ & $\begin{array}{l}N=126 \text { (Number list practic } \\
(n=40) \text {, Number-fact } \\
\text { practice }(n=44) \text {, Control } \\
(n=42))\end{array}$ \\
\hline
\end{tabular}

\section{0 weeks Researcher} (1000

ROOTS Assessment of of EARLY Numeracy Skills (RAENS) (Doabler, et al. 2012);

Students in the ROOTS

systematic. Explicit instruction: (a) Assessing Student Proficiency in Early than control students on the

condition made greater gains teacher modeling, (b) deliberate Number Sense (ASPENS) (Clarke, Gersten et NSB $((t=3.15, d f=94, p=0022)$, practice (inclscarfolding) visual al. 2011), Number Sense Brief (NSB) ASPENS (l-5.60, df=118,

representations of mathematics Screener (Jordan et al. 2008); Test of Early $p<0001$. The Time $x$ Condition (d) academic feedback. Mathematics Ability-Third Edition (Ginsburg model estimated differences in $\&$ Baroody 2003) gains between conditions of

1.94 for the NSB $(g=0.40), 21.78$ for the ASPENS $(g=0.64), 2.43$ for the TEMA-3 standard score $(g=0.31)$ and 6.50 for the RAENS $(g=1.08)$

8 weeks Researcher $(720 \mathrm{~min})$

Researchers designed

Number competencies - Number Sense There was a significant main intervention material practicing Screener (Jordan, Glutting, Ramineni \& effect for group at each time Number, Number relations, Watkins, 2010; Arithmetic Fluency (Jordan point and for each measure. For Number Fact practice and Number \& M ontani, 1997), mathematics calculation number sense, the number-list list practice. Practice conditions. achievement (Woodcock-Johnson III tests of condition outperformed the Children in both conditions Achievement (WJ-III) Standard Test Book control group (although not received the same 25-minute number-sense intervention. Lessons differed for the two Form A: Calculation Subtest (Wood cock M CGrew \& M Mathe 2007). Background Variables: Nonverbal reasoning (WPPS, Wechsler 2002), Spatial ability (The Children's mental transformation task lesson. Number-list practice, ea GreatRace Game (Ramani \& ChT) (Levine, Hensor, Taylor \& always significantly) at both postest and delayed posttest with effect sizes greater than $.25(\mathrm{ES}=32$ and $\mathrm{ES}=.26$, respectively). The effect sizes for the number-fact practice Langrock (1999), Inattentive behavior versus control were more than Siegler 2008). Number-fact $\quad$ Reading achievement (WJ-III Standard test practice: children participated in book Form A:Letter-word identification an activity that engaged quick subtest (Woodcock et al. 2007) answers to addition and

subtraction combinations that had

been thaught in the lesson that

day or in previous lesson. ( $E S=82$ and $E S=56$,

respectively) The effect of the number-list condition produced the effect of the number list over the control ( $E S=42$ ) 
Gersten, Rolfhus, Intervention for first Clarke, Decker, first graders with Wilkins \& Dimino limited number knowledge: Larg scale replication of a Randomized Controlled trial. $\mathrm{N}=994$ (intervention $\mathrm{n}=615$, students screened control $n=379$ ) nix math subtest

(Timed

computation,

Fuchs, Hamlett $\&$

Fuchs 1990;

Concepts/applicatio

ns Fuchs et al.

1990; Story

problems Jordan,

Kaplan Locuniak

\&Ramineni 2007;

The number

knowledge test

Okamoto \& Case

1996) Quantity

discrimination

(Clarke, Baker,

Cahrd \& Otterstedt

2006)

Hassinger-Das, Reading stories to kindergart low-income; low $\mathrm{N}=124$ (a storybook number Jordan \& Dyson learn math

\section{Mathematics}

instruction for

children with early

percentile)) sense intervention,
Number Sense Brief business-as-usual control)

17 weeks Teacher (1920
$\mathrm{min})$

Number Rockets the concretethe concreteed Screening measures: Timed coputation (Fuchs, Hamlett \& Fuchs, 1990):

Significant effect size of .34 which relies on concrete objects Story problems (Jordan, Kaplan, Locuniak \& research study. The effect size to promote conceptual learning. Ramineni 2007), the number knowledge The sequence of topics was test (Okamoto \& Case 1996) Quamtity

identifying and writing numbers discrimination (Clarke, Baker, Chard \&

to 99; identifying more, less, and Otterstedt 2006); Digit-span backward equal with objects; sequencing (Geary 1993). Outcome measures: Test numbers; skip counting by $10 \mathrm{~s}$, $5 \mathrm{~s}$, Early M athematics Ability - Third Edition

and $2 s$; writing number sentences; (TEMA-3) \& Assessment to explore any

place value, addition and unintended negative consequences - The

subtraction. Woodcock-Johnson III Letter/Word subtest. learn math.

vocabulary

scores $<<22$ out

\section{interventies (SNC)}

(NSB, Jordan wt al.

2010)

8 weeks Researcher (720

difficulties. virtually indentical to the mean

effect size found in the origina

efficacy study of 337 SD units.

the one can clearly infer that

the original indings were study.
Storybook Number Competencies Measures: Mathematics vocabularly (The Findings demonstrated that the yes (SNC) Intervention targeting Bracken Basic Concept Scale - Third edition. SNC intervention group

mathematics vocabularly Receptive: Quanity subtest (BBCS-3R; outperformed the other groups

knowlede (e.g. equal, more, less) Bracken 2006a), Namber sensse (ordan et on measures of mathematics

al 2010) Mathematics achievement

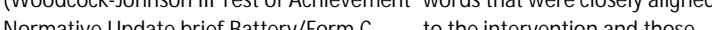

(Wormative Update brief Battery/Form C to the intervention and those

(W)-II) Applied Problmes and Calculation that werent.

$2007)$ 